\title{
Supplementary materials for: Long-term erosion of the Nepal Himalayas by bedrock landsliding: the role of monsoons, earthquakes and giant landslides.
}

\author{
By Odin Marc et al.,
}

This supplementary file contains 5 figures:

A comparison in the size-distribution of Gorkha induced landslide scar area as mapped from Roback et al., 2018 and as estimated with our geometric method from whole landslide area (Fig S1).

Landsliding between 2010-2017 and landslide frequency-size distribution derived from whole landslide areas

(Fig S2 and S3), landslide density (from landslide numbers) in 2010-2017 and the scatterplot of landslide density against monsoon rainfall metrics for 2010-2017.

Additionally, two supplementary tables describing the satellite imagery used to map the landslides between 2010-2017 and between 1972-2014 are included.

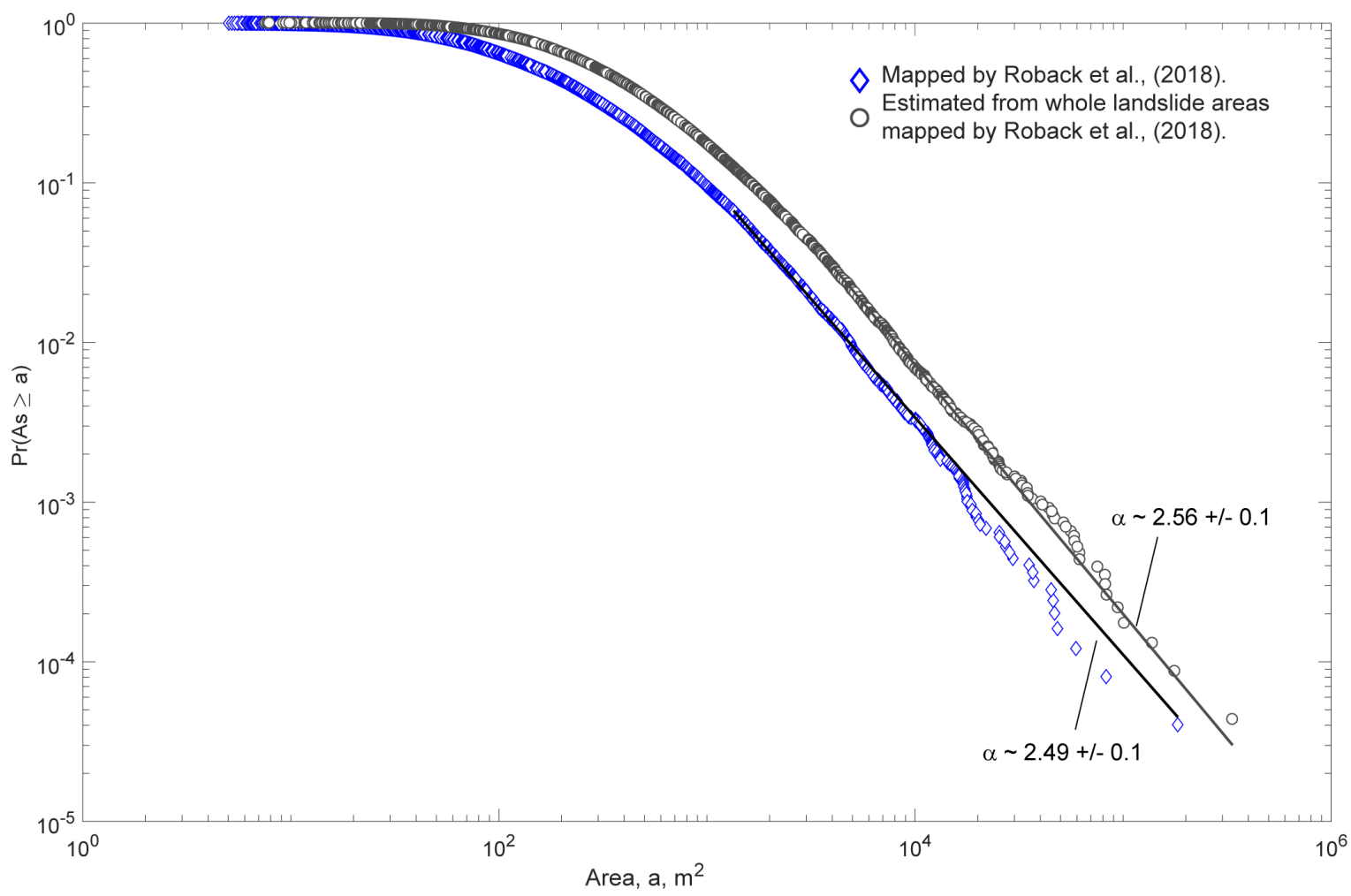

Figure Supplementary. 1

Probability of a landslide scar area being larger than a given area vs area, for the scar area mapped from Roback et al., 2018 and as estimated with our geometric method from whole landslide area. The decay exponet estimated following Clauset et al., 2009 are similar, although our method yield larger area because we impose an length-width ratio of 1.5 while the mapping from Roback et al., 2018 often had length (downslope)-width(across-slope) ratio $<1$. 

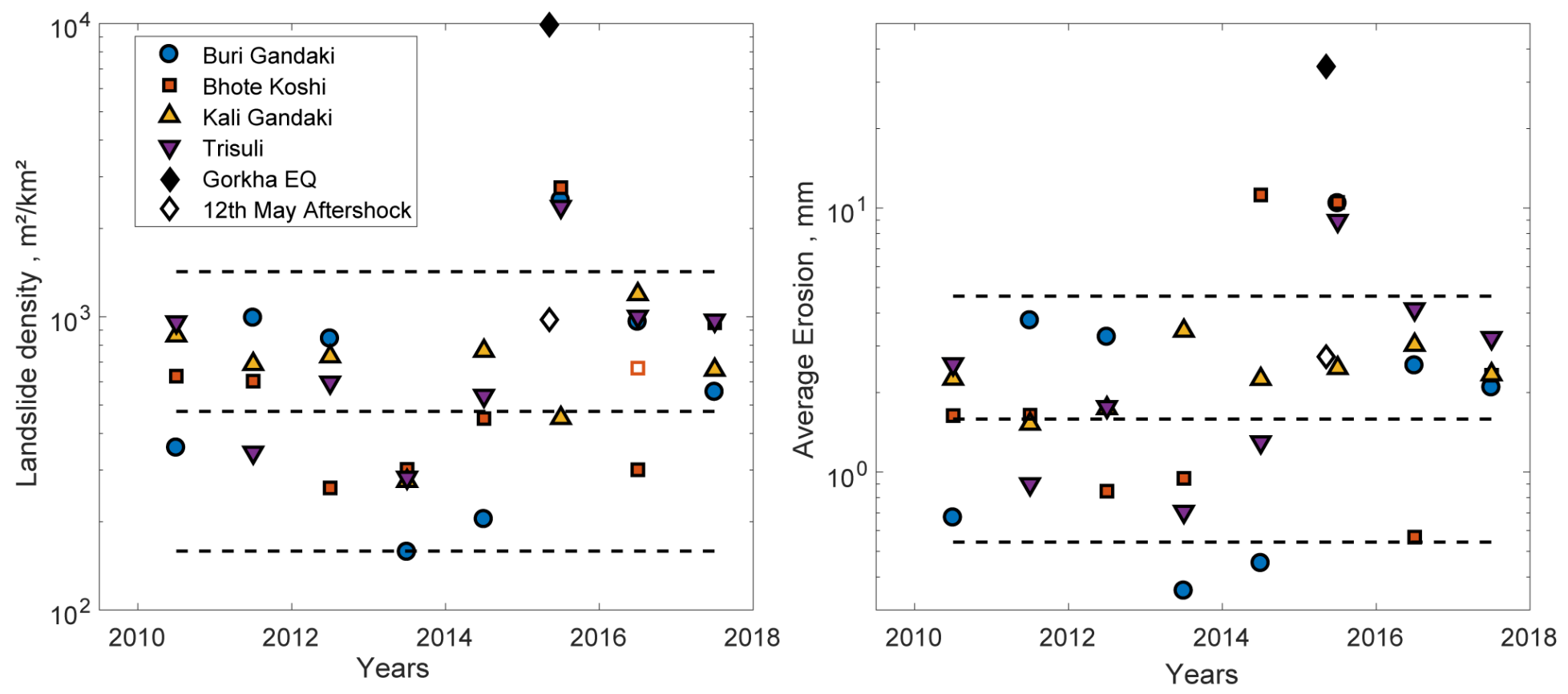

Figure Supplementary. 2

Landslide density (A) and average erosion (B) associated with the 2010-2017 monsoons in the Buri Gandaki, Bhote Koshi, Kali Gandaki and Trisuli areas (cf Fig. 1). All estimates are based on whole landslide areas. Giant landslide failure of KG (2013 and 2015) and BK (2014) have been removed (See text for details). Solid and open black squares represent the coseismic landsliding due to the Gorkha earthquake and its largest aftershock in the Bhote Koshi valley. Open orange squares indicate the 2016 BK landsliding including bank collapses that are mostly due to the 2016 glacier lake outburst flood. The dashed black lines in A, and B, are the mean values of all catchments and the mean +/- 2sigma from 2010-2014.

Note that although the spatio-temporal pattern is similar to the ones derived from landslide scar (cf., Fig 2), the density and erosion are much larger. The mean annual erosion rates are near $2 \mathrm{~mm} / \mathrm{year}$, and spread from $\sim 0.5$ to $\sim 4 \mathrm{~mm} / \mathrm{yr}$, substantially larger than typical erosion rates obtained from suspended sediment budget $(\sim 0.1-1 \mathrm{~mm} / \mathrm{yr})$ 


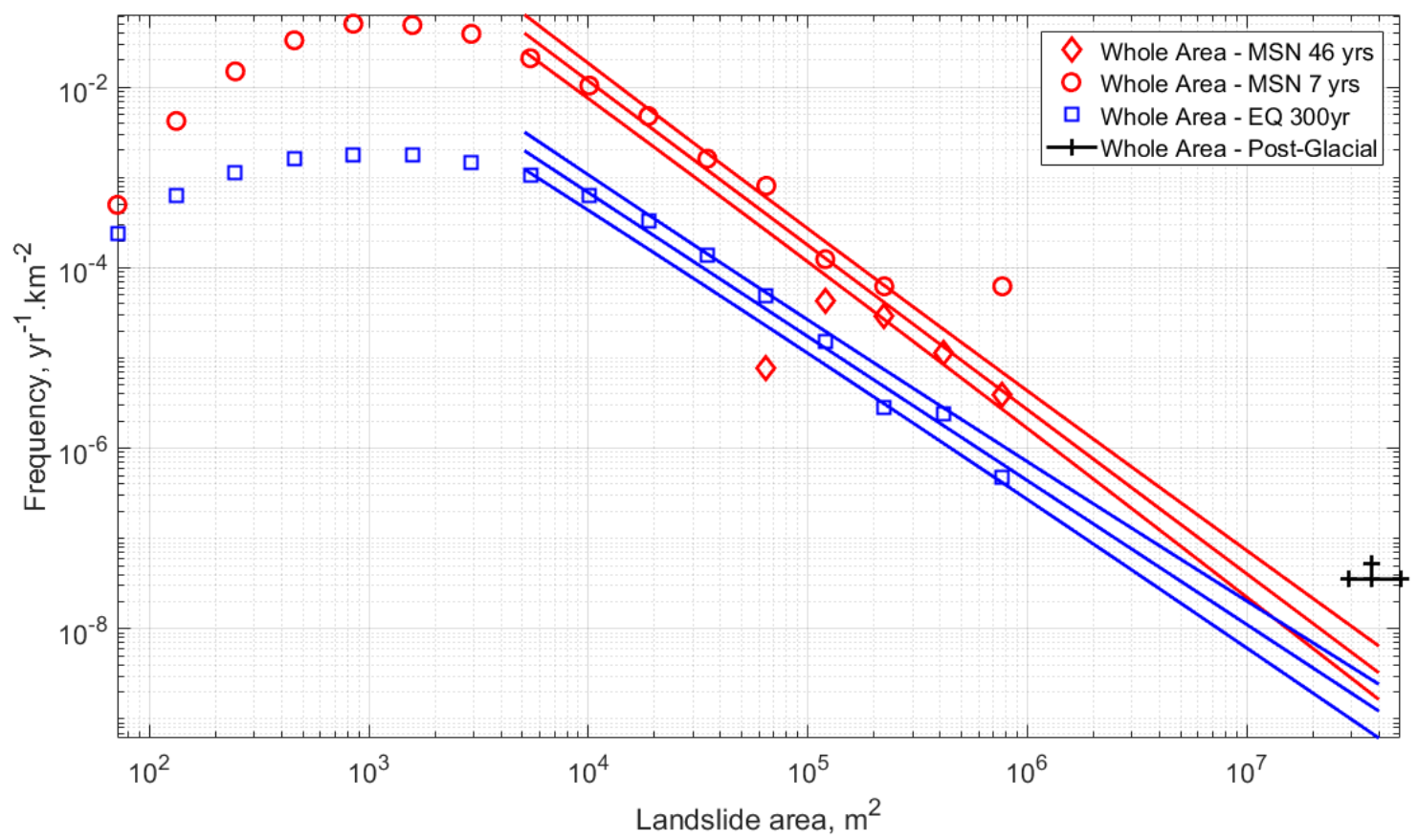

Figure Supplementary 3

Same as main text Figure 5, but for whole landslide area. Note the wider roll-over, steeper decay for both earthquake- and monsoon-induced landslides $\left(\alpha_{\mathrm{EQ}}=-1.52, \alpha_{\mathrm{M}}=-1.7\right)$ and larger offset with the estimated frequency of giant deposits $(>10$ fold). These steep decay exponents would imply that the small landslides dominates the budget of monsoon induced landslides, and thus that total erosion does not increase significantly with sampling time, and would be around $\sim 3 \mathrm{~mm} / \mathrm{yr}$ for short and long timescales (see also the annual estimate of average erosion with this approach in Fig S1). These two results would be inconsistent with the erosion rates determined other various timescales by different methods (Cf., main text).

Instead, we consider that these rates are biased because of the inclusion of substantial runout and deposit areas in landslide areas, biasing the volume estimates and frequency-size distribution. 

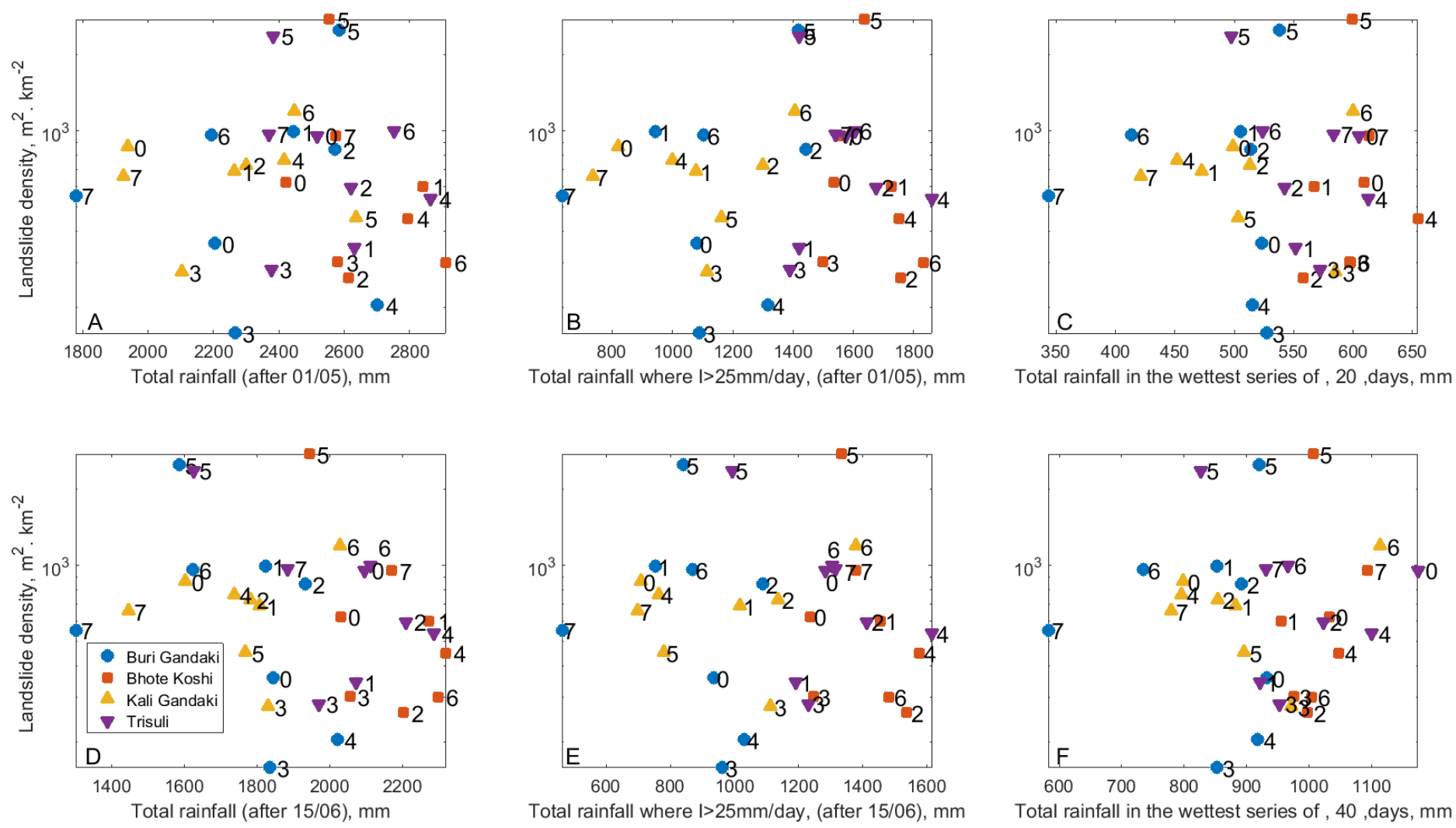

Figure Supplementary 4

Landslide density (from scar area) against total rainfall after the $1^{\text {st }}$ of May (A) and the $15^{\text {th }}$ of June (D), total rainfall of days with mean intensity larger than $25 \mathrm{~mm} /$ day, after $1^{\text {st }}$ of May (B) and $15^{\text {th }}$ of June (E) and the total rainfall during the wettest 20 (C) and 40 (F) consecutive days. These monsoon metrics were derived from daily estimates between $1^{\text {st }}$ of May and 30 of September from GSMaP Version 6 ungaged standard product. We calibrated the rain-rate with the function $\mathrm{Rcal}=6 * \mathrm{R}^{\wedge} 0.7$, as this function allowed the best match between the Cumulative Distribution Function of GSMaP rain rate and of the mean rain rate of 6 rain gauges in the Bhote Koshi, for the monsoons of 2015 and 2016. We average 4 to 9 pixel $\left(0.1-0.1^{\circ}\right)$ of the GSMaP products relevant to the Rapid Eye tile location. The number to the right of each symbol indicates the year of the monsoon (relative to 2010). There is no clear correlation for any metrics, even when ignoring the exceptional landsliding for 2015. This may be due to biased rainfall estimates and/or the need of a more specific hydro-meteorologic modelling. 


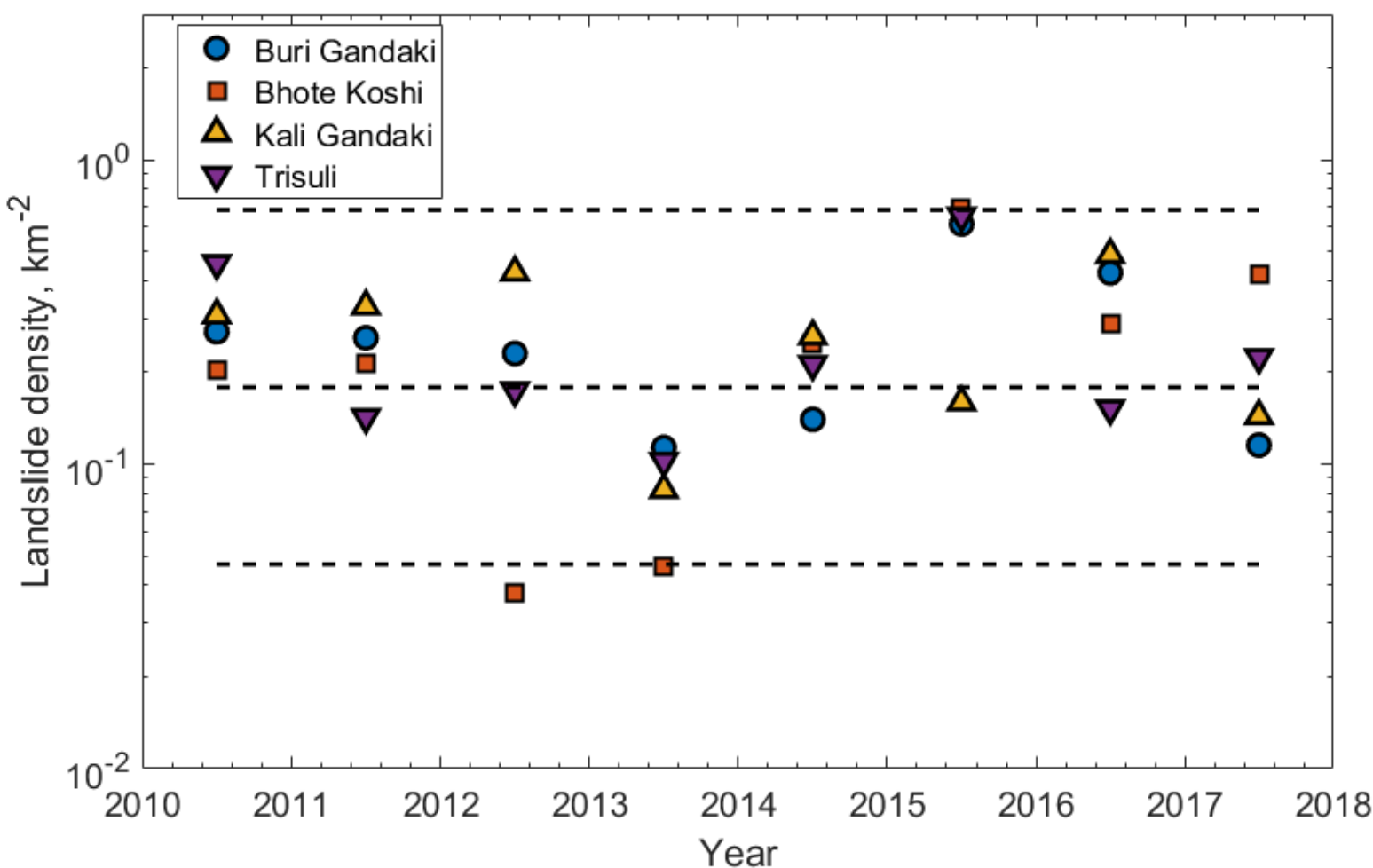

Figure Supplementary 5

Number of landslide per unit area (density) in the four valley of our study. The dashed black lines are the mean values of all catchments and the mean $+/$ - 2sigma from 2010-2014, where mean and standard derivation are based on the log-transformed values. The spatio-temporal pattern is similar to the ones observed for area or volume. The scatter is larger however, and the 2015 monsoon produced a landslide density above average but that departs less from the previous years distribution (only 2 standard deviation) than what we observed for area and volume. This may be due to the highest sensitivity of this metric to the smallest landslides that are the most difficult to map. 


\begin{tabular}{|c|c|c|c|c|c|c|c|c|c|}
\hline & 2009 & 2010 & 2011 & 2012 & 2013 & 2014 & 2015 & 2016 & 2017 \\
\hline $\begin{array}{l}\text { Kali } \\
\text { Gandaki } \\
4452225\end{array}$ & & $\begin{array}{l}\text { R1-03/31; } \\
\text { R4-04/27; } \\
\text { R4-12/07; }\end{array}$ & & $\begin{array}{l}\text { R3-03/22; } \\
\text { R4-05/24; } \\
\text { R2-11/05; }\end{array}$ & $\begin{array}{l}\text { R4-03/25; } \\
\text { R4-10/25; }\end{array}$ & R2-11/13; & $\begin{array}{l}\text { R4-05/10; } \\
\text { R3-05/28; } \\
\text { R3-10-08; }\end{array}$ & $\begin{array}{l}\text { R1-10/31; } \\
\text { R1-11/05; }\end{array}$ & R5-11/14; \\
\hline $\begin{array}{l}\text { Buri } \\
\text { Gandaki } \\
4552106\end{array}$ & $\begin{array}{l}\text { R3-10/17; } \\
\text { R3-11/10; }\end{array}$ & $\begin{array}{l}\text { R5-10/26; } \\
\text { R4-11/04; }\end{array}$ & R4-10/08 & $\begin{array}{l}\text { R4-09/25; } \\
\text { R3-12/04; }\end{array}$ & R2-10/23; & $\begin{array}{l}\text { R1-04/21; } \\
\text { R4-10/17; } \\
\text { R2-11/03; }\end{array}$ & $\begin{array}{l}\text { R3-04/10; } \\
\text { R2-05/03; } \\
\text { R5-05/25; } \\
\text { R1-10/06; } \\
\text { R3-10/27; }\end{array}$ & R4-11/02; & R5-11/18; \\
\hline $\begin{array}{l}\text { Trisuli } \\
4552007\end{array}$ & $\begin{array}{l}\text { R1-11/08; } \\
\text { R3-11/10; }\end{array}$ & R3-10/26; & R4-10/27; & $\begin{array}{l}\text { R2-03/11; } \\
\text { R2-11/19; }\end{array}$ & R2-11/11; & $\begin{array}{l}\text { R2-03/29; } \\
\text { R2-11/03; } \\
\text { R5-12/28; }\end{array}$ & $\begin{array}{l}\text { R5-05/25; } \\
\text { R5-10/05; } \\
\text { R3-10/27; }\end{array}$ & $\begin{array}{l}\text { R3-11/01; } \\
\text { R1-11/04 }\end{array}$ & R4-11/12 \\
\hline $\begin{array}{l}\text { Bhote } \\
\text { Koshi } \\
4551910\end{array}$ & AS-10/23 & $\begin{array}{l}\text { R2-04/01; } \\
\text { R4-10/25; } \\
\text { AS-11/11; }\end{array}$ & $\begin{array}{l}\text { R2-10/11; } \\
\text { AS-10/20; }\end{array}$ & $\mathrm{R} 1-02 / 25$ & $\begin{array}{l}\text { R1-03/12; } \\
\text { R2-11/06; }\end{array}$ & R3-10/11 & $\begin{array}{l}\text { R3-05/04; } \\
\text { R2-05/27; } \\
\text { R4-05/28; } \\
\text { R1-10/01; }\end{array}$ & R2-10/31; & $\begin{array}{l}\text { R3-09/11; } \\
\text { R2-11/10; }\end{array}$ \\
\hline
\end{tabular}

Supplementary Table 1:

List of the Rapid Eye images used for producing the multi-temporal landslide inventories in the 4 valleys of interest. Each valley has a Rapid-Eye ID number, and for each year we indicate the satellite number (From the Rapid Eye constellation 15) and date of the image we used (MM/DD). Exceptionally, the swath of the imagery in the Bhote Koshi in 2010 and 2011 was slightly different, with $\sim 15-20 \%$ of the tile not covered. Thus we used 2012 Rapid Eye imagery for the mapping of fresh landslides and Aster (15m resolution) images of the areas, acquired in 2009, 2010 and 2011 for resolving the occurrence dates of these landslides. Imagery was always selected for its lowest amount of clouds, and multiple images in similar year were used to reduce the obstructed surface. Images between October and March typically have less than a few percent of cloud cover, while the ones from May to September can reach 15-30\% cloud cover, but mainly concentrated above high peaks and ridge lines, where mapping is difficult to not possible anyway.

\begin{tabular}{|l|l|l|l|l|}
\hline Year & Imagery : Satellite_SwathID_MM/DD/YY & Clouds & Shadows & Comments \\
\hline 1972 & L1_153040_11/28+L1_152040_12/15+L1_151041_12/14 & CC $1.5 \%$ & SH $\sim 5 \%$ & Snow on the range and behind it. \\
\hline $1977-79$ & L3_153040_01/26/79+L2_152040_02/13/77+L3_151041_01/24/79 & CC $5 \%$ & SH $\sim 5 \%$ & Some stripe offset (eastern corner) \\
\hline 1988 & L5_142040_19/10+L5_141040_12/10+L5_141041_12/10 & CC $4 \% ;$ & SH 1.5\% & \\
\hline $2001-2002$ & L7_142040_11/03/02+L7_141040_10/24/01+L7_141041 10/27/02 & CC $1.5 \%$ & SH $\sim 1.5 \%$ & \\
\hline 2014 & L8_142040_12/30+L8_141040_12/23+L8_141041_11/21 & CC $3 \%$ & SH 6\% & \\
\hline
\end{tabular}

Supplementary Table 2:

Summary of the characteristics of the Landsat images used to produce the 46-yr inventory of large landslides. The different Landsat multispectral sensors have the following spatial resolution used for mapping: L1 $-3=60 \mathrm{~m}$, L4-8=30. Additionally pan-sharpening with a $15 \mathrm{~m}$ panchromatic band was used for the L7 and L8 images. For each decade we give the sensor, acquisition dates and the amount of cloud cover and shadows preventing mapping, expressed in \% of the whole AOI ( $10,000 \mathrm{~km}^{2}$ not considering the glacial and periglacial areas). 